\title{
Modificadores restritivos do nome
}

Restrictive modifiers of the noun

Márcia Teixeira NOGUEIRA (UFC) marciatn@gmail.co

José Alber Campos UCHOA (UFC) alber.letras@yahoo.com.br

Recebido em: 18 de maio de 2018. Aceito em: 02 de jul. de 2019.
NOGUEIRA, Márcia Teixeira; UCHOA, José Alber Campos. Modificadores restritivos do nome. Entrepalavras, Fortaleza, v. 9, n. 2, p. 173-194, maio-ago/2019.

Resumo: Este artigo trata da indeterminação de fronteira categorial entre dois modificadores restritivos do nome: o aposto e o adjunto adnominal. O objetivo é trazer discussão em torno do que aproxima e o que distancia adjunto adnominal e aposto. Fazemos, inicialmente, uma breve revisão bibliográfica sobre como esses dois termos são analisados na sintaxe tradicional, isto é, em gramáticas tradicionais e compêndios de análise sintática da língua portuguesa. Analisamos, em seguida, a caracterização que os modificadores do nome recebem na sintaxe estrutural, com atenção especial ao tratamento dado à distinção entre adjunto adnominal e aposto em gramáticas descritivas de Língua Portuguesa. Por último, tratamos da análise desses modificadores restritivos do nome no âmbito da sintaxe funcional, mais especificamente nas propostas teóricas de Halliday (1985), da Gramática Sistêmico-Funcional, e de Keizer (2007), da Gramática DiscursivoFuncional.

Palavras-chave: Modificador restritivo. Adjunto adnominal. Aposto. 
V. 9 (2)

$173-194$

maio-ago

2019

Abstract: This article deals with the indetermination of the categorial boundary between two restrictive modifiers of the noun: the appositive and the adnominal. The goal is to discuss what approaches or distinguishes appositive and adnominal. We initially make a brief review of how these two terms are analyzed in traditional syntax, that is, in traditional grammars and compendia of syntactic analysis of the Portuguese language. Then we analyze the characterization that the noun modifiers receive in the structural syntax, with special attention to the treatment given to the distinction between adnominal and appositive in descriptive grammars of Portuguese language. Finally, we deal with the analysis of these restrictive modifiers of the noun in the scope of functional syntax, more specifically in the theoretical proposals of Halliday (1985), Systemic Functional Grammar, and Keizer (2007), Discourse Functional Grammar.

Keywords: Restrictive modifier of noun. Adnominal. Appositive.

\section{Introdução}

Na estrutura de um Sintagma Nominal (SN), os determinantes, modificadores e complementos costumam ser definidos por critérios semânticos, distribucionais e funcionais, cuja aplicação, por vezes, apenas desnuda uma indeterminação de fronteira, em virtude da dificuldade em identificar tais categorias por meio uma propriedade que lhes seja privativa. Este artigo trata de uma dessas indeterminações de fronteira categorial entre os constituintes do SN, particularmente entre os modificadores restritivos do nome. A Nomenclatura Gramatical Brasileira (NGB) consigna, entre os termos ditos acessórios da oração, dois termos com potencial de restringir a extensão referencial do nome: o adjunto adnominal e o aposto. Nosso objetivo é trazer a análise e discussão, entre gramáticos e linguistas, sobre o que aproxima e o que distancia adjunto adnominal e aposto, que entendemos como dois tipos de modificadores restritivos do nome.

Fazemos, inicialmente, uma breve revisão sobre como esses dois termos são definidos e analisados na sintaxe tradicional, isto é, em gramáticas tradicionais e manuais de análise sintática da língua portuguesa, editados antes e depois da Portaria que instituiu a NGB. Partimos dessa revisão crítica das contribuições dos gramáticos, porque acreditamos que, além do livro didático, é essa a fonte mais consultada por professores e alunos da educação básica na disciplina de Língua Portuguesa.

Analisamos, em seguida, a caracterização que os modificadores do nome recebem na sintaxe estrutural, com atenção especial ao tratamento dado à distinção entre adjunto adnominal e aposto em gramáticas descritivas de Língua Portuguesa. 
Por último, tratamos dessa mesma distinção no âmbito da sintaxe funcional, mais especificamente nas propostas teóricas de Halliday (1985; 2004), da Gramática Sistêmico-Funcional, e de Keizer (2007), da Gramática Discursivo-Funcional.

\section{A perspectiva da sintaxe tradicional sobre modificadores restritivos do nome: aposto e adjunto adnominal}

Nas gramáticas e manuais de análise sintática, editados antes da reformulação da terminologia gramatical, proposta pela NGB, o aposto era considerado um adjunto atributivo, função que corresponde essencialmente ao que hoje denominamos de adjunto adnominal.

Passos (1865, p.35) define aposto como termo que favorece a ideia de restrição e, surpreendentemente, começa por aplicar essa denominação ao tipo de aposto que hoje classificamos como especificativo ${ }^{1}$. Para ele, "Apposto (posto junto) - Nome apposto é o substantivo que se ajunta a outro na mesma relação como seu modificativo". E exemplifica: "O poeta Camões, o rio Amazonas, os capitães Pedro e João, os doutores Augusto e Jorge, o vapor Cruzeiro do Sul, a corveta Imperial Marinheiro".

Em sua Gramática Descritiva, Maciel (1918, p.274-279) apresenta o aposto como uma das formas de expressão do chamado adjunto atributivo. Segundo define o autor, adjunto atributivo é toda palavra ou expressão que, embora modifique o substantivo, não constitui uma asserção. A aposição que Maciel denomina de específica é a usada para especificar e restringir o conceito de um termo. Pode ser personativa ou locativa. A aposição personativa pode ser constituída por um nome personativo aposto imediatamente a um pronome pessoal ou a um apelativo, como nos exemplos: "Eu Aníbal peço a paz; a rainha Vitória, o papa Leão XIII, o professor Horácio". A aposição locativa é constituída por um nome locativo aposto imediatamente a um apelativo, tal como em: "o rio Purus, o rio Danúbio, a serra Leoa"; ou por um termo locativo ligado, às vezes, a uma das palavras: cidade, vila, aldeia, ilha, através da preposição de, como em: a cidade de Paris, a vila do Rosário, a ilha de Marajó etc.

Pacheco e Lameira (1907, p.490) também abrigam o aposto na classe dos modificadores identificados como adjuntos atributivos, definidos pelos gramáticos como o adjetivo ou um seu equivalente que se una a um nome ou pronome para indicar-lhe uma qualidade. O gramático

${ }^{1}$ Nas gramáticas tradicionais de língua portuguesa, o aposto dito explicativo (loose apposition), e não o especificativo (close apposition), tem estatuto mais central no conceito de aposto. 
V. 9 (2)

$173-194$

também se reporta ao tipo de construção apositiva bastante usada com a função atributiva, como, por exemplo, em: "a falsa de sua sogra". Alfredo Gomes (1930, p.323) também vê o aposto como um adjunto atributivo, expresso por um substantivo, sem o intermédio da preposição. O gramático considera a expressão cidade de Roma como uma locução. Para o autor, o termo principal, Roma, tem forma de adjunto restritivo, e o termo secundário, cidade, é um termo acessório, que tem, todavia, a função de regente. Na locução, o termo secundário é apenas um adjunto aposto². Segundo Alfredo Gomes, de acordo com a lógica, diríamos "Roma, cidade, é a capital do mundo católico", tal como em latim Urbs Roma.

Souza Lima (1937, p.43) afirma que a aposição caracterizase pelo fato de os dois substantivos designarem o mesmo objeto, ressaltando que, em geral, o primeiro substantivo traz sua denominação genérica, e o segundo, a sua denominação específica ou individual, tal como observamos em o rio Tejo. Alude o gramático à possibilidade de o aposto ligar-se ao fundamental através da preposição, como em: cidade de Roma, mês de setembro, virtude da caridade, pobre de mim. Para o autor, na designação cidade de Roma, os dois substantivos encerram um único conceito (cidade $=$ Roma), todavia o mesmo não ocorre com cidade de São Paulo, uma vez que não há identidade conceitual entre os dois substantivos (cidade $=$ São Paulo), pois São Paulo apenas "empresta seu nome a uma cidade, mas não é ele próprio a cidade". Souza Lima analisa o sintagma de São Paulo como complemento restritivo. No entanto, o gramático considera a possibilidade de analisarmos o que seria um complemento restritivo como aposto, quando é omitida a preposição de em construções como Teatro João Caetano. Notamos aqui um conflito entre critérios morfológicos e semânticos na análise das construções.

Eduardo Carlos Pereira (1945, p. 232-233) não subclassifica o aposto, nem mesmo distinguindo entre um tipo como em Salomão, filho de David, e outro como em a casa Garraux ou o rio Amazonas. Ao definir o aposto como "substantivo que modifica outro, sem o auxílio de preposição" e considerar que, em a casa do Garraux e o rio das Amazonas, é destruída a aposição, certamente o gramático faz referência à aposição como processo de construção sintática, e não ao termo sintático denominado aposto, tal como distingue Nogueira (1999). Nos dois exemplos de aposição desfeita, o gramático utilizou também

\footnotetext{
${ }^{2}$ Nessa explicação feita pelo gramático, se estabelece uma confusão terminológica entre as denominações termo primário, termo secundário, termo acessório, termo regente, adjunto restritivo e adjunto aposto.
} 
determinante, parecendo mesmo que aí não temos as formas comumente utilizadas, mas algo discursivamente diferente, mais poético e, de fato, despido da qualidade de aposição. Mas, e se tivéssemos a estrutura comumente guarnecida de preposição, por exemplo, em o rio das Velhas, designação toponímica constante nos manuais de Geografia, ou se a tal casa fosse conhecida como do Garraux? O gramático também não distingue complemento, termo que prefere, de adjunto, denomina uns de complemento essencial e outros de complemento acidental, e põe o aposto entre os complementos atributivos, sejam explicativos ou restritivos.

Oiticica (1948, p.223), em seu Manual de Análise, define o aposto como um substantivo explicativo, quase um adjetivo, que se põe ao lado de outro substantivo para explicar-lhe uma das qualidades, sem, entretanto, mencioná-la como característica.

Em sua Gramática Normativa da Língua Portuguesa para curso superior, Silveira Bueno (1944, p.287) inclui o aposto e o vocativo entre os complementos acidentais atributivos, uma vez que, segundo o gramático, tais elementos são modificadores do nome, funcionando como determinantes do sentido daqueles a que se referem.

A indeterminação entre os termos abrigados, nas gramáticas tradicionais, no amplo conceito de adjunto atributivo permanece após a publicação da Nomenclatura Gramatical Brasileira (NGB). Almeida (1985, p.435) considera o aposto como um tipo de adjunto adnominal constituído por um grupo de palavras em aposição, que explicam um ou mais termos expressos na oração. Para o autor, o aposto vem depois do termo fundamental, colocando-se após a palavra modificada, por meio de vírgula. Entretanto, ao descrever construções apositivas em referências personativas, Almeida analisa como aposto a palavra que representa um título profissional ou hierárquico, tal como nos exemplos: o professor Carlos Almeida, o tenente José Joaquim, o conde Ramiro³. O gramático apresenta, também, o aposto ligado ao fundamental mediante a preposição de, tal como em: Rua da Consolação, Duque de Caxias, Praça dos Gusmões, acrescentando que essa preposição é desnecessária.

Se, por exemplo, em vez de o professor Carlos Almeida, o tenente José Joaquim e a rua da Consolação, disséssemos simplesmente $o$ professor, o tenente ou a rua, provavelmente isso se ajustaria à escolha de uma expressão referencial que apenas retomasse referentes já

${ }^{3}$ Quanto a esse ponto, Goes e Palhano (1960) e Almeida (1985) divergem da maioria dos gramáticos ao analisarem o substantivo comum como aposto. Sobre tal divergência na identificação dos termos ditos fundamental e aposto, remetemos a Amini Hauy (1987). 
V. 9 (2)

$173-194$

maio-ago

2019

compartilhados. Por outro lado, numa referência um pouco mais precisa, se fizéssemos uso dos nomes próprios Carlos Almeida, José Joaquim e Consolação, a atribuição de referência seria facilitada, mesmo sem uma referência explícita anterior. Em construções apositivas como o teatro José de Alencar e o romance Iracema, o uso dos nomes próprios têm sua referência inicialmente categorizada pelos nomes comuns (teatro e romance), e posteriormente restringida pelos nomes próprios. Utilizados sozinhos, os nomes próprios dependeriam de informação compartilhada que permitisse a atribuição de referência ao teatro e ao romance, respectivamente, e não aos indivíduos José de Alencar e Iracema. O uso de uma construção com aposto especificativo é um recurso referencial que opera com uma categorização seguida de uma especificação, muito mais do que restrição tal como opera um adjunto adnominal. Colocase, em cada contexto de uso, uma decisão pragmática que decorre da estimativa do falante sobre contextos e conhecimentos compartilhados. Por esse motivo, numa frase como Iracema fez grande sucesso em todo o Brasil, o nome próprio, não garante, em si mesmo, uma adequada atribuição do referente, pois falta a este uma categorização inicial, feita pelo nome comum: trata-se da índia Iracema, do romance Iracema ou da música Iracema, de Jackson do Pandeiro?

O caráter nominal, essencialmente substantivo, é frequentemente apontado como característica de um modificador restritivo como o aposto, enquanto o valor de adjetivo é atribuído ao modificador restritivo adjunto adnominal. Rocha Lima (1987, p.225) define o aposto como um termo de caráter nominal que acompanha um substantivo ou um pronome a fim de individualizar ou esclarecer o seu sentido. O gramático chama a atenção para o fato de substantivo fundamental e aposto designarem o mesmo ser. No manual intitulado Novas Lições de Análise Sintática, Gama Kury (1987, p.57) vê o aposto como um termo acessório, necessariamente substantivo, que explica, desenvolve ou resume uma ideia fundamental contida num termo de valor substantivo. Um tipo de aposto descrito pelo gramático é o aposto de especificação, representado por um termo preposicionado ou não que especifica ou individualiza um substantivo de sentido genérico, como em "cidade de Roma". Gama Kury ressalta que são igualmente apositivas as construções utilizadas por escritores modernos, nas quais ocorre a inversão dos termos em aposição, verificando-se uma ausência de pausa, tal como na frase: "Mestre Gaudêncio curandeiro gingava" (Graciliano Ramos), em vez de Mestre curandeiro Gaudêncio gingava. 
Em sua Moderna Gramática Portuguesa, Bechara (1989, p.213) apresenta, entre os tipos de aposto, o especificativo, em que um nome próprio se une a um nome comum que lhe indica a espécie a que pertence, como em rio Amazonas, montes Pirineus, o poeta Castro Alves, tecidos Aurora, lojas Paulista, cervejaria Brahma. Bechara acrescenta que o aposto especificativo pode ligar-se ao fundamental através da preposição de e cita o gramático Silva Dias, para quem depende da arbitrariedade do uso o empregar-se, em alguns casos, o de definitivo, como em a cidade de Lisboa; e, em outros, a aposição, como em o rio Tejo. Segundo Bechara, é igualmente aceitável considerar-se a expressão encabeçada pela preposição como adjunto adnominal ou como aposição, embora o gramático diga inclinar-se para essa última análise.

Segundo Cunha (1994, p.162), o aposto tem o mesmo valor sintático do termo a que se refere, podendo estar presente em vários termos da oração. Com base nas ideias do gramático Galichet (1968 apud Cunha, 1994), Cunha assume que o adjetivo não pode exercer a função de aposto, porque ele não designa o ser, mas, sim, uma característica do ser.

Na Moderna Gramática Brasileira, Luft (1985, p.142) também vê o aposto como um tipo de adjunto adnominal explicativo; e Gladstone Chaves de Melo (1978, p.138) também considera o aposto como um tipo de adjunto adnominal expresso por substantivo não preposicionado, ligado apenas ideologicamente ao termo fundamental.

O exame que levamos a efeito nesta seção mostra que falta clareza: a) nas definições de aposto e na distinção de seu estatuto como termo oracional distinto de outros modificadores restritivos do nome, tais como os adjuntos adnominais; b) nas divisões internas, ou subclassificações do aposto, que o aproximam de outras categorias funcionais como o adjunto adnominal, o predicativo e o adjunto adnominal; c) no caso do tratamento do aposto, na identificação dos termos ditos fundamental (núcleo) e aposto em construção apositiva especificativa como o rio Tejo. Parece que precisamos de algumas mudanças no tratamento pouco respeitoso para com o aposto, termo oracional extremamente comum, em nada menos importante que os adjuntos adnominais.

Aprofundaremos, na próxima seção, a discussão sobre as semelhanças e diferenças entre aposto e adjunto adnominal na função de modificadores restritivos do nome na perspectiva da sintaxe estrutural. 
V. 9 (2)

$173-194$

maio-ago

2019

\section{A perspectiva da sintaxe estrutural sobre os modificadores restritivos do nome}

Nesta seção, analisamos a contribuição de algumas gramáticas descritivas que, segundo orientações teóricas diferentes, trataram da indeterminação de fronteira entre dois modificadores restritivos do nome: aposto e adjunto adnominal.

Em Bloomfield (1979, p.186), a aposição é identificada como um tipo de parataxe, isto é, uma construção em que as formas não estão conectadas por nenhuma outra construção, mas simplesmente por uma pausa tonal. Para o estruturalista norte-americano, na aposição, formas parataticamente unidas são gramaticalmente, mas não semanticamente, equivalentes. Bloomfield destacou o caráter de parêntese de um grupo aposicional, quando este aparece em posição inclusa, ou seja, como parte de uma forma linguística maior, tal como em: João [,] o pobre rapaz [,] fugiu [.]. Interessa-nos, particularmente, neste artigo, o que Bloomfield denominou aposição fechada (close apposition), isto é, a aposição sem pausa tonal, que pode ser exemplificada nas expressões Rei João, Monte Everest, Sr. Churchill.

Segundo Matthews (1981, p. 223), há algumas evidências de que a aposição fechada proposta por Bloomfield, na verdade, foge à definição de aposição como uma relação de parataxe, uma vez que as formas unidas parecem constituir um único sintagma e, pelos próprios testes bloomfieldianos, de natureza endocêntrica. O autor demonstra que, ao contrário do que ocorre no caso paradigmático de aposição, em uma aposição fechada como Monte Everest, a ordem é fixa. Há, ainda, restrições relativamente ao primeiro componente, já que somente ele pode ser suprimido, quando se diz, por exemplo, Eles escalaram o Everest ou quando não se diz, por exemplo, Montanha Everest. Além disso, os componentes em Monte Everest não estabelecem uma referência separadamente, e nem é possível introduzir uma pausa tonal entre ambos, como em Eles escalaram o Monte, Everest. Tais restrições parecem sinalizar uma indeterminação de fronteira entre esse tipo de construção apositiva e as locuções substantivas, que correspondem, segundo Matthews, ao grau máximo de codificação, pois é difícil dizer, seguramente, quando estamos lidando com um único sintagma, uma única expressão referencial, e não com duas.

Em língua portuguesa, essa indeterminação de fronteira entre aposição e locução substantiva com nomes próprios personativos e locativos pode ser ilustrada em casos como Casas Bahia, Lojas Americanas 
ou, com o uso da preposição, como Avenida da Universidade, em que o segundo elemento integra-se na codificação lexical de nomes próprios (Casas Bahia, Lojas Americanas, Avenida da Universidade), não podendo ser analisados, composicionalmente, como adjunto adnominal ou como aposto dentro de um SN.

Macambira (1987, p. 341), ao tratar de aspectos semânticos, alude à semelhança entre adjunto adnominal, aposto e predicativo, ressaltando que, conceitualmente, esses termos se equivalem. Do ponto de vista sintático, o aposto especificativo pode, segundo Macambira, acompanhar-se de preposição, como em a cidade de Fortaleza. Macambira aponta dois tipos de aposto: a) aposto dependente ou pausado, constituído de substantivo colocado após outro e separado através de ligeira pausa, marcada pela vírgula, como, por exemplo, em Anchieta, o apóstolo do Brasil, compôs um poema nas areias da praia; b) aposto independente ou não pausado, representado por um nome próprio, personativo ou locativo que restringe a significação de um substantivo a que se apõe, tal como nos exemplos o professor Deoclécio, a cidade de Fortaleza. Segundo Macambira, a preposição de, algumas vezes empregada no aposto independente, não é obrigatória, podendose dizer, por exemplo, a serra de Baturité ou a serra Baturité. O linguista cearense lembra, ainda, que a relação fundamental - aposto é invertida quando transformamos o aposto dependente em independente, tal como temos em A cidade de Fortaleza é um sonho tropical e Fortaleza, a cidade, é um sonho tropical. Mesmo tendo afirmado que o aposto independente pode ser considerado como adjunto adnominal, buscando apoio para seu posicionamento na Real Academia Espanhola, Macambira assume que é mais preciso analisá-lo como aposto, em virtude da possibilidade de transformá-lo em predicativo. No que concerne aos aspectos mórficos, Macambira apresenta as diversas estruturas em que o aposto se manifesta. Segundo ele, podem exercer a função de aposto: substantivo, palavra substantivada, pronome, infinitivo, oração reduzida infinitiva, oração subordinada. O termo fundamental pode ser um substantivo, um pronome ou equivalente, uma oração e, até mesmo, um advérbio, podendo, inclusive, estar implícito, como em Homem honrado, (tu) saberás honrar teu compromisso.

No Dicionário de Linguística e Gramática, Câmara Jr. (1986, p.47) chama a atenção para o fato de se ter, na aposição, não um sintagma, mas uma sequência centrípeta, isto é, que gira em torno de um centro. Segundo o linguista, esse tipo de construção distingue-se das 
V. 9 (2)

$173-194$ sequências de caráter centrífugo, em que cada membro tem seu ponto de referência, como em Carlos Gomes, José de Alencar, Pedro Américo são algumas de nossas glórias nacionais.

Perini (1989, p.182) prefere não incluir o aposto entre os termos internos ao sintagma nominal. O autor defende seu posicionamento, argumentando que o aposto tem uma estrutura interna muito semelhante à do próprio sintagma nominal. Assim, considerando o alto grau de paralelismo estrutural entre sintagma nominal e aposto, o linguista prefere ver esse último como um caso de repetição de sintagma nominal, e não como um termo independente.

Para descrever o aposto em língua portuguesa, Carone (1988, p.66) recorre ao quadro de hierarquia sintática proposto pelo linguista Lucien Tesnière. Tesnière (1976, p.163) vê a aposição como um substantivo que, integrando o nó substantival, está em conexão semântica direta e horizontal com o substantivo nuclear a que se refere, tratando-se, sintaticamente, de um caso de hipóstase. Adverte para o fato de que o substantivo em aposição não está em conexão com o verbo, mas com o substantivo que exerce o papel de um seu actante. Assim, embora admita que, do ponto de vista estrutural, esses dois substantivos sejam iguais entre si, Tesnière ressalta que eles não são necessariamente idênticos: o substantivo nuclear é um actante do verbo, e o substantivo em aposição é apenas um atributo desse substantivo nuclear. Tesnière lembra que, por ser uma conexão horizontal, a aposição distingue-se do atributo e do epíteto, que estão em relação vertical com o substantivo centro do nó substantival. Carone (1988, p.66) chama a atenção para o fato de a expressão conexão horizontal parecer contraditória. De fato, Tesnière (1976, p.163) emprega a palavra conexão para designar uma relação vertical, isto é, de subordinação. A autora afirma acreditar que apostos e epítetos assemelham-se no que diz respeito ao seu estatuto permanente de subordinação.

A descrição que a autora faz da formação do aposto propõe, em síntese, uma fusão entre duas orações e uma translação de segundo grau que faz o verbo de uma dessas orações, a que apresenta predicado nominal, e, consequentemente, toda a oração em que ele se encontra, comportar-se como um adjetivo. O aposto é visto, então, como um resíduo de uma oração adjetiva com predicado nominal, após o apagamento do pronome relativo e do verbo ser. Enquanto o chamado aposto explicativo (pausado) origina-se de uma oração explicativa; o aposto restritivo (não pausado) origina-se de uma oração restritiva. 
Há, nessas abordagens descritivas, divergências em torno da análise do aposto como termo interno ou externo ao sintagma nominal. Para Câmara Jr., tem-se, na aposição, uma sequência e não um sintagma. O aposto, então, repetiria a função do substantivo a que se refere, embora mantivesse, com ele, uma identidade referencial. De modo semelhante, Perini (1989) analisa a aposição como um mecanismo de repetição de função sintática. Por outro lado, há os que consideram o aposto como um constituinte do sintagma nominal, como vemos em Carone (1988, p.66). Essas duas descrições nos parecem conflitantes, já que a noção de repetição de função não é compatível com uma descrição que inclua o aposto entre os termos internos ao sintagma nominal cujo núcleo é o próprio termo que ele modifica.

A análise da aposição segundo o paradigma de uma linguística biestrutural consegue ser elucidativa até certo ponto, mas seria necessário propormos tantas transformações quantas fossem necessárias para explicar a diversidade de construções apositivas existentes. Além disso, supomos que há divergências quanto a considerar a relação de aposição como coordenação ou como subordinação. Coordenação, porque, conforme descreve Silva Dias (1978), uma estrutura apositiva origina-se a partir de duas orações coordenadas. Subordinação, porque, como esclarece Carone (1988), tal estrutura advém da redução de uma oração subordinada adjetiva.

Podemos concluir que a adoção de paradigmas diferentes dentro da teoria sintática pode levar a posicionamentos inteiramente discrepantes com relação ao estatuto sintático de uma expressão apositiva. Dessa forma, quando a análise se volta para a descrição das estruturas sintagmáticas nos contextos sintáticos em que ocorrem, a aposição pode, inclusive, ser vista como um mecanismo de repetição de constituintes oracionais. Por outro lado, quando a análise tem natureza lexical e paradigmática, porque se volta para o plano das potencialidades no que diz respeito às relações de dependência sintática e semântica entre os termos, tal como na gramática de valência desenvolvida por Tesnière, podemos afirmar que um vocábulo em aposição integra o "nó substantival", na condição de um atributo do substantivo nuclear.

\section{A perspectiva funcionalista sobre os modificadores restritivos do nome}

Como dissemos, nos estudos sobre as construções apositivas, distingue-se um tipo de aposição em que as unidades não se separam por uma pausa tonal. É a chamada aposição fechada ou close apposition, como propõe Bloomfield (1979). De acordo com os gramáticos Quirk et 
v. 9 (2)

173-194

maio-ago

2019

al. (1985), esse tipo de aposição pode ser chamada de restritiva, já que os elementos apositivos constituem uma única unidade de informação, estando em uma mesma unidade tonal, o que é indicado, no discurso oral, pela ausência de uma pausa ou, na escrita, de um sinal de pontuação entre os elementos apositivos.

Alguns linguistas, tais como Burton-Roberts (1987), Lago (1991) e Rodriguez (1989) não admitem a existência teórica da aposição restritiva por defenderem a correferência estrita entre as unidades apositivas como propriedade central da aposição, e esta, como condição incompatível com o papel de um modificador restritivo do nome. De acordo com Lago (1991), o caráter não restritivo da aposição provém da exigência de correferência entre os termos apositivos. Para ele, dois termos em aposição devem ter, cada um, separadamente, o mesmo poder designativo, isto é, devem ser nocionalmente equivalentes. Por essa razão, o segundo termo não pode ser um subconjunto no interior de um conjunto (o que caracteriza uma modificação de caráter restritivo). Se o segundo termo na construção tem um poder designativo mais forte que o do núcleo, como é o caso, por exemplo, em o mês de janeiro, a condição de correferência desaparece automaticamente, o que, para o autor, prova que a aposição restritiva não pode existir.

Rodriguez (1989) analisa que El mes de enero (o mês de janeiro) e La ciudad de Córdoba (a cidade de Córdoba) têm estrutura sintática de núcleo-modificador, em que a preposição de é um marcador de transposição de enero (janeiro) da função de substantivo para o de um adnominal. A construção La ciudad de Paris (a cidade de Paris) corresponde, segundo Rodriguez (1989), a Os mistérios de Paris. Em ambas, há um complemento determinativo. Apenas a relação semântica nelas é diferente, pois, só na primeira, há identidade. Para Rodriguez, tanto em la ville de Paris (a cidade de Paris), como em el niño de Pedro (o filho de Pedro), o segundo termo restringe a extensão do primeiro, mas somente na primeira construção, pois podemos dizer Paris es una ciudad (Paris é uma cidade), mas não é possível dizer Pedro es un niño (Pedro é um filho). Embora haja, no primeiro caso, uma estrutura equacional quanto ao seu semantismo (equivalência gênero-espécie), não podemos afirmar, segundo Rodriguez, que há correferência, pois, em el mes de enero (o mês de janeiro), ao dizermos el mês (o mês), não nos referimos, especificamente, a enero (janeiro).

$\mathrm{Na}$ Gramática Sistêmico-Funcional proposta por Halliday (1985, 2004), identificamos parâmetros diferenciados relativos ao tipo 
de relação lógico-semântica e ao tipo de codificação sintática que podem nos ajudar a compreender a existência de modificadores apositivos restritivos. Para Halliday, o componente lógico do sistema linguístico responde pelas relações semântico-funcionais entre palavras, grupos ou sintagmas, e orações. O linguista postula duas dimensões para a interpretação de tais relações: o sistema de interdependência (ou tático) e o sistema lógico-semântico. O sistema de interdependência define a relação de hipotaxe, estabelecida entre um elemento dependente e o seu dominante; e a relação de parataxe, mantida entre termos de igual estatuto, um iniciador e um continuador. Enquanto a relação paratática é logicamente simétrica e transitiva, a relação de hipotaxe é assimétrica e não transitiva. Além das relações de interdependência, um grupo ou oração pode, através de um encaixamento (embedding), integrar a estrutura de outro grupo que, por sua vez, é constituinte de uma oração.

De acordo com o sistema lógico-semântico, as relações são agrupadas em dois tipos fundamentais: a expansão e a projeção. A expansão pode ocorrer através de uma elaboração (=), quando um elemento expande outro, reformulando-o, especificando-o em mais detalhes, comentando-o ou apresentando exemplos; de uma extensão $(+)$, quando acrescentamos algum elemento novo, apresentamos uma exceção ou alguma alternativa; ou de um encarecimento (x), quando fornecemos algum traço circunstancial relativo a tempo, lugar, modo, causa ou condição. A relação de projeção ocorre quando uma oração ou grupo projeta-se por meio de outra que a apresenta como uma locução, uma ideia, ou um fato.

De acordo com Halliday, a aposição enquadra-se no tipo de relação lógico-semântica de elaboração, manifestada através de uma exposição ou uma exemplificação. Ocorre que esse quadro de relações lógicas não define o estatuto sintático da aposição, uma vez que apresenta tal processo muito mais pelo seu valor semântico de expansão por elaboração. Entendemos que construções ditas apositivas podem manifestar uma mesma relação lógico-semântica em estruturas sintáticas diferentes. Analisando, por exemplo, a expressão The job of cleaning the barracs ( $\mathrm{O}$ trabalho de limpar o quartel), temos uma relação lógico-semântica de elaboração numa estrutura apositiva encaixada, em que a especificação é apresentada, nos termos de Halliday (1985, p.222), como um elemento posmodificador na estrutura do grupo nominal que é sujeito na oração. 
V. 9 (2)

$173-194$

maio-ago

2019

Embora uma cláusula incorporada, não finita, com uma preposição seja geralmente de significado circunstancial e, portanto, de encarecimento, existe outro tipo [...] que está elaborando; nomeadamente aqueles onde a relação é apositiva, e.g. o trabalho de limpar o quartel onde o trabalho consiste em limpar o quartel. ${ }^{4}$

Para Halliday (1985, p. 199), o padrão básico das relações de interdependência, que define as relações paratáticas como simétricas, e as hipotáticas como assimétricas, pode ser modificado pela natureza da relação lógico-semântica estabelecida entre os elementos primário e secundário. Dessa forma, mesmo que, por definição, uma relação paratática seja simétrica, se o tipo de relação lógico-semântica entre os termos for assimétrica, podemos verificar a impossibilidade de suprimir algum deles sem acarretar prejuízos à oração resultante.

No quadro teórico da Gramática Discursivo-Funcional, Keizer (2007) reconhece que as construções apositivas restritivas não constituem um grupo homogêneo e propõe os seguintes tipos de estruturas possíveis no inglês:

a. The actor Orson Welles

(O ator Orson Welles)

b. The word recession

(A palavra recessão)

c. Orson Welles the actor

(Orson Welles o ator)

d. Actor Orson Welles

(Ator Orson Welles)

e. My friend Orson Welles

(Meu amigo Orson Welles)

f. My friend the actor

$N$

(Meu amigo o ator)
Tipo 1a: $\operatorname{det}+N+N_{P}$

Tipo 1b: $\operatorname{det}+N+N$

Tipo 2: $N_{P}+\operatorname{det}+N$

Tipo 3: $N+N_{P}$

Tipo 4a: poss $+N+N_{P}$

Tipo 4b: poss $+N+d e t+$

Numa proposta inicial de caracterização dessas construções, a autora expõe os seguintes critérios com base na literatura sobre o tema. Quanto às características formais, as aposições restritivas: a) contêm dois elementos nominais; b) não há nenhum conectivo entre

\footnotetext{
4 Tradução nossa de Halliday (1985, p.222): Although a non-finite embedded clause with a preposition is generally circumstantial in meaning, and hence enhancing, there is one other type (...) that is elaborating; namely those with of where the relation is appositive, e.g. the job of cleaning the barracs where the job consists in cleaning the barracks.
} 
eles (tal como the city of Rome); c) um dos elementos é um nome próprio (tipos 1a, 2, 3 e 4a), ou outro elemento que seja considerado como tendo referente único (tipo 1b); o outro elemento é um nome contável; d) na língua oral, os dois elementos não são separados por pausa. As propriedades semânticas frequentemente mencionadas são: a) ambos os elementos referem uma mesma entidade; b) há uma relação semântica (de modificação, predicação ou especificação) entre os dois elementos.

De acordo com a autora, há consenso em torno dos critérios relativos à entonação (os dois elementos pertencem a uma mesma unidade tonal, que codifica uma mesma unidade de informação) e à classe e à forma dos elementos. Todavia, Keizer identifica divergências de análise no que concerne: a) à estrutura sintática e à identificação do núcleo $\left(\mathrm{SN}_{\text {núcleo }}+\mathrm{SN}_{\text {mod }} ; \mathrm{SN}_{\text {mod }}+\mathrm{SN}_{\text {núcleo }} ; \mathrm{SN}_{\text {núcleo/mod }}+\mathrm{SN}_{\text {núcleo/mod }} ;\right.$ Det $\left.\left[\mathrm{N}_{\text {mod }}+\mathrm{N}_{\text {núcleo }}\right]\right)$; b) à omissibilidade sintática (para identificar-se o elemento nuclear da construção); c) à referência (se os elementos são correferenciais ou não); d) à omissibilidade semântica (com ou sem mudança semântica na sentença resultante); e) à reversibilidade dos elementos.

De acordo com Keizer, nenhum elemento da construção apositiva restritiva é, por si mesmo, referencial, isto é, usado referencialmente. Apenas a construção como um todo pode ser dita referencial. Logo, para Keizer, esse tipo de construção não é constituído por dois elementos correferenciais. Se, nos testes de omissibilidade, as sentenças resultantes são aceitáveis, para a autora, isso apenas mostra que cada um dos elementos pode ser usado para referir uma mesma entidade, tal como a construção de que eles fazem parte.

(1) O ator Orson Welles escreveu e dirigiu Cidadão Kane.

(1a) $O$ ator escreveu e dirigiu Cidadão Kane.

(1b) Orson Welles escreveu e dirigiu Cidadão Kane.

Segundo Keizer, essa possibilidade não surpreende, já que os elementos da aposição restritiva são usados para descrever atributos de uma mesma entidade e, sendo de natureza nominal, qualquer um deles pode ser usado como um SN para referir essa entidade na sentença.

Com base na discussão a respeito dos critérios apontados acima, Keizer reformula a caracterização inicial das construções apositivas restritivas em termos de propriedades formais e semânticas. As propriedades formais se repetem: a) a construção contém dois 
V. 9 (2)

$173-194$

maio-ago

2019 elementos nominais, que se abrigam em uma única unidade de entonação; b) não há conectivo entre eles, um dos elementos é um nome próprio ou tem referência única, e o outro elemento é um nome contável. Do ponto de vista semântico, encontramos a seguinte reformulação: a) nenhum dos dois elementos é referencial, embora ambos possam ser usados independentemente, para referir uma mesma entidade (mesmo não tendo as mesmas condições de felicidade em dado contexto); b) a relação semântica entre os elementos é de modificação.

Como nenhum dos elementos apositivos tem referência independente, nas representações subjacentes propostas por Keizer, também se encontra assumido que o determinante da construção não tem como escopo apenas o primeiro elemento, mas todo o conjunto formado pelos dois elementos nominais atributivos da construção.

Adotando também uma abordagem de categorização não discreta para o tema aposição, Keizer assinala que uma construção apositiva restritiva prototípica contém, em geral, um elemento descritivo e um elemento de referência única que, juntos, constituem uma expressão ótima de referência definida, que permite uma identificação inequívoca do referente pretendido. Todavia, aposições restritivas menos típicas podem não ser expressões definidas; podem, por exemplo, não apresentar um elemento descritivo (Mr. Brown, Dr. Jonh) ou podem não exibir um nome próprio ou um elemento de referência única (Meu amigo o poeta). Para a autora, a escolha do tipo de aposição restritiva não é arbitrária, pois, dentro de uma situação discursiva, o falante escolhe o mais eficiente meio linguístico à disposição para referir, introduzir ou descrever um referente discursivo em particular.

Keizer (2007) analisa, à parte, as construções apositivas com a preposição of (de), que costumam ser tratadas como aposições restritivas. Essas construções se aproximam de outras construções nominais com preposição que, como vimos, também nas gramáticas de língua portuguesa, representam uma fronteira tênue e difícil com a modificação e a complementação, reveladas na identificação dos termos aposto, adjunto adnominal e complemento nominal.

Como sabemos, um sintagma preposicionado (SP) pode funcionar como modificador ou como complemento de um núcleo, mas essa distinção nem sempre é fácil. Para Keizer, uma propriedade em comum entre as construções com complemento e com modificador é que, nesses casos, não há dúvida com relação ao núcleo, que será sempre a primeira unidade da construção. A diferença entre construções 
com complemento e construções com modificador reside na função (complemento ou adjunto) do SP e no estatuto da preposição (elemento lexical indicando posse, isto é, uma preposição "cheia"; ou elemento semanticamente vazio, um mero índice de função).

Por outro lado, nas construções apositivas com a preposição, nem sempre é fácil identificar o núcleo, já que os testes de permuta e supressão dos elementos apositivos revelam uma sentença resultante que é sintaticamente correta e semanticamente aceitável, já que ambos podem ser usados para referir uma mesma entidade. Em a cidade de Roma, tanto cidade como Roma (que é uma cidade), podem ser empregados para referir uma mesma entidade, com alterações apenas no nível discursivo.

Mesmo considerando graus de omissibilidade dos elementos da construção apositiva com a preposição, tal como no caso de close appositions, Keizer assume que, também nessas construções, os elementos não têm referência independente. E, mesmo considerando que o núcleo da construção é sempre o primeiro elemento nominal, a autora admite que a forma dessas construções varia bastante, a depender do tipo de elemento que lhe serve de especificação, isto é, do elemento que a preposição encabeça. A autora chama a atenção para o fato de que o segundo elemento nominal é analisado como um predicado nominal, não como um SP, e que of não é representado como uma preposição encabeçando um SP (ou seja, a preposição não forma com o segundo elemento nominal um constituinte), mas é um elemento conectivo, um elemento funcional sem conteúdo semântico, inserido como meio sintático para indicar uma relação de especificação entre dois elementos nominais.

Analisando um conjunto de construções em que dois elementos nominais são ligados pela preposição of, Keizer (2007, p. 83) propõe as seguintes representações subjacentes:

a. Construções com núcleo-modificador the mosaics of Venice (os mosaicos de Veneza) $\left[_{\mathrm{SN}}\left[\left[_{\text {Det }}\right.\right.\right.$ the $]\left[_{\mathrm{ExtN}}\left[{ }_{\mathrm{N}}\right.\right.$ mosaics $]\left[_{\mathrm{SP}}[\mathrm{p}\right.$ of $\left.\left.\left.]\left[_{\mathrm{SN}}\left[{ }_{\mathrm{N}} \text { Venice }\right]\right]_{\text {Poss }}\right]\right]\right]$

b. Construções com núcleo-complemento the production of penicillin (a produção de penicilina) $\left[_{\mathrm{SN}}\left[_{\text {Det }}\right.\right.$ the $]\left[_{\mathrm{ExtN}}\left[{ }_{\mathrm{N}}\right.\right.$ production $]\left[_{\mathrm{SP}}[\mathrm{P}\right.$ of $\left.\left.\left.]\left[_{\mathrm{SN}}[\mathrm{N} \text { penicillin }]\right]_{\mathrm{Pat}}\right]\right]\right]$

the father of the bride (o pai da noiva)

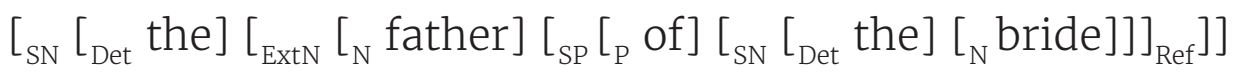


V. 9 (2)

173-194

maio-ago

2019

\section{c. Construções partitivas}

one of the stallholders (um dos vendedores)

$\left[_{\mathrm{SN}}\left[{ }_{\mathrm{Num}}\right.\right.$ one $]\left[_{\mathrm{ExtN}}\left[\left[_{\mathrm{Ne}}\right]\left[_{\mathrm{SP}}\left[{ }_{\mathrm{P}}\right.\right.\right.\right.$ of $\left.\left.]\left[_{\mathrm{SN}}\left[\left[_{\text {Det }} \text { the }\right]\left[_{\mathrm{N}} \text { stallholders }\right]\right]_{\mathrm{Ref}}\right]\right]\right]$ most of his plays (a maioria dos jogos)

$\left[_{S N}[\right.$ most $]\left[_{\text {ExtN }}\left[{ }_{N} e\right]\left[_{S P}\left[{ }_{P}\right.\right.\right.$ of $\left.\left.\left.]\left[_{S N}[\text { Det } \text { his }]\left[{ }_{N} \text { plays }\right]\right]_{\text {Ref }}\right]\right]\right]$

\section{d. Construções com núcleo-qualificador}

a book of comics (um livro de humor)

$\left[_{S N}\left[{ }_{\text {Det }}\right.\right.$ a $]\left[\left[_{N}\right.\right.$ book $\left[{ }_{S P}[\right.$ of $]\left[{ }_{N}\right.$ comics $\left.\left.\left.]\right]\right]\right]$

a word of gratitude (uma palavra de gratidão)

$\left[_{\mathrm{SN}}[\mathrm{Det}\right.$ a $]\left[_{\mathrm{N}}\right.$ word $\left[_{\mathrm{SP}}[\mathrm{p}\right.$ of $]\left[_{\mathrm{N}}\right.$ gratitude $\left.\left.\left.]\right]\right]\right]$

e. Aposições com of

the city of Rome (a cidade de Roma)

$\left[_{\mathrm{SN}}\left[{ }_{\text {Det }}\right.\right.$ the $]\left[_{\text {ExtN }}\left[_{\mathrm{N} \text {-head }}\right.\right.$ city $]\left[_{\mathrm{EL}}\right.$ of $]\left[_{\mathrm{N}}\right.$ Rome $\left.\left.]\right]\right]$

his role of military leader and negotiator

(seu papel de líder militar e negociador)

$\left[_{\mathrm{SN}}\left[{ }_{\text {Det }}\right.\right.$ his $]\left[_{\text {ExtN }}\left[_{\mathrm{N} \text {-head }}\right.\right.$ role $]\left[_{\mathrm{EL}}\right.$ of $]\left[_{\text {ExtN }}\left[\left[\left[_{\mathrm{A}}\right.\right.\right.\right.$ military $]\left[_{\mathrm{N}}\right.$ leader $\left.]\right]$ and $\left[{ }_{N}\right.$ negotiator $\left.\left.\left.]\right]\right]\right]$

Nas construções com núcleo-modificador (os mosaicos de Veneza), que estão mais próximas do que os gramáticos costumam identificar como adjunto adnominal, o primeiro elemento nominal não é derivado (isto é, não há um verbo cognato) e não é relacional (isto é, não é um nome transitivo). Semanticamente, a natureza da relação é de posse em seu sentido amplo.

Nas construções com núcleo-complemento (a produção de penicilina), o núcleo é tipicamente um nome relacional (transitivo), e o elemento of, mesmo esvaziado de sentido, pode ser considerado uma preposição. Nesse tipo de construção, os nomes cognatos de verbos transitivos são vistos igualmente como transitivos (relacionais), nomes com valência semântica (em relações parte-todo, parentesco, atributo-todo).

Nas construções partitivas (a maioria dos jogos), o SP funciona como complemento do nome e a relação é tipicamente de inclusão (parte-todo, membro-conjunto).

Nas construções com núcleo-qualificador (um livro de humor), o SP não é referencial, e o segundo elemento nominal é, em geral, um nome massivo. 
Finalmente, nas construções apositivas com preposição ( $a$ cidade de Roma), o primeiro elemento nominal funciona como núcleo, e o segundo, como um elemento nominal que especifica esse núcleo, designado, na nomenclatura tradicional, como aposto. Além disso, a preposição é analisada por Keizer como um elemento separado, com função conectiva puramente sintática.

\section{Considerações finais}

Embora, por vezes, coloquem ambos - aposto e adjunto adnominal - no abrigo de um rótulo categórico mais amplo - em gramáticas anteriores à NGB, como adjuntos atributivos; e, em gramáticas posteriores à NGB, como adjunto adnominal, os gramáticos apontam para uma diferença relevante no entendimento do tipo de restrição que operam esses dois tipos de modificadores do nome, tais como a diferença entre designar o ser - aposto, ou uma característica do ser-adjunto adnominal (CUNHA, 1994, p.162), o que leva, por exemplo, à contestação, entre alguns gramáticos, de que o adjetivo exerça a função de aposto.

Assim, enquanto o adjunto adnominal opera, no discurso, a restrição do conjunto potencial de referentes do nome comum por meio de atributos, o aposto opera essa restrição por meio de uma designação mais específica do referente, em geral, por meio de um nome próprio (a cidade nordestina - adjunto adnominal; a cidade de Fortaleza - aposto).

Discordamos, portanto, da ideia defendida por Rodriguez (1989), que analisa as construções El mes de enero (o mês de janeiro) e La ciudad de Córdoba (a cidade de Córdoba) como correspondentes à estrutura que abriga um adjunto adnominal. Para a autora, nos dois casos, temos um mesmo tipo de modificador restritivo - e nenhum deles se concebe como aposto pela ausência da correferencialidade estrita entre os nomes, e a preposição de é um marcador dessa transposição da função de substantivo para a de adnominal. Para Rodriguez (1989), El mes de enero (o mês de janeiro) e La ciudad de Córdoba (a cidade de Córdoba) correspondem a Os mistérios de Paris. Nas duas construções, há um complemento determinativo. E esclarece que apenas a relação semântica nelas é diferente, pois há relação de identidade apenas nas duas primeiras. Ora, se a autora reconhece que há identidade apenas nessas duas primeiras construções (o mês de janeiro e a cidade de Córdoba), porque não considerar que nelas temos, sim, construções apositivas que, mesmo se distanciando da representação prototípica dessa categoria 
v. 9 (2)

173-194

maio-ago 2019

(NOGUEIRA, 1999), já que se encontram numa estrutura morfossintática típica de modificação restritiva com adjunto adnominal, preservam essa identidade ou equivalência semântica (ainda que parcial) entre as unidades, que é o traço mais recorrente na caracterização de uma construção apositiva e do tradicionalmente chamado aposto?

Neste estudo, de natureza essencialmente bibliográfica, podemos concluir que o chamado aposto especificativo - sem deixar de ser aposto - e o adjunto adnominal são ambos modificadores restritivos do nome, mas essa modificação restritiva deve ser interpretada, acima de tudo, com a consideração do funcionamento discursivo, isto é, das propriedades semânticas e discursivas identificadas em cada contexto de uso linguístico, e não com a fixação de estruturas sintáticas que, ao serem consideradas como privativas de uma determinada função, escondem a natureza estratégica da formulação e codificação linguística na produção dos atos discursivos, o que pode ser percebido em um modelo de gramática de componentes (pragmática, semântica, morfossintaxe) funcional e estrategicamente integrados, mas conceitualmente independentes.

\section{Referências}

ALFREDO GOMES, A. Gramática portuguesa. 20. ed. Rio de Janeiro: Francisco Alves, 1930.

ALMEIDA, N. M. Gramática metódica da língua portuguesa. 33. ed. São Paulo: Saraiva, 1985.

BECHARA, E. Moderna gramática portuguesa. 33. ed. São Paulo: Nacional, 1989. BLOOMFIELD, L. Language. London: George Allen; Unwin, 1979.

BURTON-ROBERTS, N. Nominal apposition. In: Foundations of language, v. 13, p. 391-419, 1987.

CÂMARA JR., J. M. Dicionário de linguística e gramática. 13. ed., Petrópolis: Vozes, 1986.

CARONE, F. B. Morfossintaxe. São Paulo: Ática, 1988.

CHAVES DE MELO, G. Gramática fundamental da língua portuguesa. 3. ed. Rio de Janeiro: Livro Técnico, 1978.

CUNHA, C. F. da. Gramática da língua portuguesa. 12. ed. Rio de Janeiro: FAE, 1994.

PEREIRA, E. C. Gramática expositiva (curso superior). São Paulo: Nacional, 1945. 
GAMA KURY, A. Novas lições de análise sintática. 3a. ed., São Paulo: Ática, 1987.

GOES, C.; PALHANO, H. Gramática da língua portuguesa. Rio de Janeiro: Francisco Alves, 1960.

HALLIDAY, M. A. K. An introduction to functional grammar. London: Edward Arnold, 1985.

HALLIDAY, M. A. K.; MATHIESSEN, C. An introduction to functional grammar. 3rd. ed. London/New York: Hodder Arnold, 2004.

HAUY, A. B. Da neccessidade de uma gramática-padrão de língua portuguesa. 3. ed., São Paulo: Ática, 1987.

KEIZER, E. The English Noun Phrase - The nature of linguistic categorization. Cambridge: Cambridge University Press, 2007.

LAGO, J. A special type of nonrestrictive modification. Verba, Santiago de Compostela, v. 18, p. 487-520, 1991.

LUFT, C. P. Moderna gramática brasileira. Porto Alegre: Globo, 1985.

MACAMBIRA, J. R. A estrutura morfo-sintática do português: uma aplicação do estruturalismo linguístico. 5. ed. São Paulo: Pioneira, 1987.

MACIEL, M. de A. Gramática descritiva. Rio de Janeiro: Francisco Alves, 1918.

MATTHEWS, P. H. Syntax. New York: Cambridge University Press, 1981.

NOGUEIRA, M. T. A aposição não-restritiva em textos do português contemporâneo escritos no Brasil. 1999. 241f. Tese (Doutorado em Linguística e Língua portuguesa) - Faculdade de Ciências e Letras, Universidade Estadual Paulista Júlio de Mesquita Filho, Araraquara, 1999.

OITICICA, J. R. L. Manual de análise (léxica e sintática). 6. ed. Rio de Janeiro: Francisco Alves, 1942.

PACHECO, S.; LAMEIRA, A. Gramática da língua portuguesa. 3. ed. Rio de Janeiro: Francisco Alves, 1907.

PASSOS, J. A. Diccionário grammatical portuguez. Rio de Janeiro: Antonio Gonçalvez Guimarães Livraria, 1865.

PERINI, M. A. Sintaxe portuguesa: metodologia e funções. São Paulo: Ática, 1989.

QUIRK, R. et al. A comprehensive grammar of the English language. London/ New York: Longman, 1985.

ROCHA LIMA, C. H. Gramática normativa da língua portuguesa. 2. ed. Rio de Janeiro: José Olympio, 1987.

RODRIGUEZ, C. F. De nuevo sobre la aposición. Verba, Sevilla, v. 16, p. 215236, 1989. 
v. 9 (2)

173-194 maio-ago 2019

SILVA DIAS, E. da. Sintaxe histórica portuguesa. 5. ed. Lisboa: Livraria Clássica, 1918.

SILVEIRA BUENO, F. Gramática normativa da língua portuguesa (curso superior). São Paulo: Acadêmica/Saraiva, 1944.

SOUZA LIMA, M. P. de. Gramática portuguesa. 2. ed. Rio de Janeiro: José Olympio, 1937.

TESNIÈRE, L. Éléments de syntaxe structurale. 2. ed. Paris: Klincksieck, 1976. 